Review

\title{
Can Skin Exposure to Sunlight Prevent Liver Inflammation?
}

\section{Shelley Gorman ${ }^{1, *}$, Lucinda J. Black ${ }^{1}$, Martin Feelisch ${ }^{2}$, Prue H. Hart ${ }^{1}$ and Richard Weller ${ }^{3}$}

1 Telethon Kids Institute, University of Western Australia, 100 Roberts Rd, Subiaco, Western Australia 6008, Australia; E-Mails: lucinda.black@telethonkids.org.au (L.J.B.); prue.hart@telethonkids.org.au (P.H.H.)

2 Clinical and Experimental Sciences, Faculty of Medicine, University of Southampton, Southampton General Hospital, Southampton, SO16 6YD, UK; E-Mail: M.Feelisch@soton.ac.uk

3 University of Edinburgh, MRC Centre for Inflammation Research, Edinburgh, EH16 4TJ, UK; E-Mail: richard.weller@ed.ac.uk

* Author to whom correspondence should be addressed;

E-Mail: shelley.gorman@telethonkids.org.au; Tel.: +61-8-9489-7884 (ext. 7884);

Fax: +61-8-9489-7990.

Received: 28 March 2015 / Accepted: 27 April 2015 / Published: 5 May 2015

\begin{abstract}
Liver inflammation contributes towards the pathology of non-alcoholic fatty liver disease (NAFLD). Here we discuss how skin exposure to sunlight may suppress liver inflammation and the severity of NAFLD. Following exposure to sunlight-derived ultraviolet radiation (UVR), the skin releases anti-inflammatory mediators such as vitamin $\mathrm{D}$ and nitric oxide. Animal modeling studies suggest that exposure to UVR can prevent the development of NAFLD. Association studies also support a negative link between circulating 25-hydroxyvitamin D and NAFLD incidence or severity. Clinical trials are in their infancy and are yet to demonstrate a clear beneficial effect of vitamin $D$ supplementation. There are a number of potentially interdependent mechanisms whereby vitamin D could dampen liver inflammation, by inhibiting hepatocyte apoptosis and liver fibrosis, modulating the gut microbiome and through altered production and transport of bile acids. While there has been a focus on vitamin $\mathrm{D}$, other mediators induced by sun exposure, such as nitric oxide may also play important roles in curtailing liver inflammation.
\end{abstract}

Keywords: sunlight; vitamin D; nitric oxide; liver; inflammation; non-alcoholic fatty liver disease 


\section{What Is Non-Alcoholic Fatty Liver Disease?}

Non-alcoholic fatty liver disease (NAFLD) is a spectrum of disorders ranging from simple steatosis to non-alcoholic steatohepatitis. NAFLD is linked with obesity, type-2 diabetes and metabolic syndrome, and is now the most prevalent liver disorder in western countries. It is caused by excessive accumulation of fat (triglycerides) in the liver [1] and results in abnormal lipid metabolism, but the underlying molecular mechanisms are under debate [2,3]. In the double-hit hypothesis, lipid accumulation in the liver is followed by the release of pro-inflammatory mediators that induce inflammation, hepatocyte death and fibrosis [4]. Others suggest that free fatty acids and cytokines (such as tumour necrosis factor- $\alpha$, $\mathrm{TNF} \alpha$ ) are hepatotoxic and underpin the molecular pathogenesis of NAFLD [5]. A third hypothesises is that multiple hits are required, including genetic, environmental and nutritional factors, involving diverse parallel processes including fatty acids, bacterial lipopolysaccharides, cytokines, chemokines and adipokines, which acting in concert induce NAFLD [6,7]. Here we discuss the evidence for sunlight-derived mediators, such as vitamin D and nitric oxide (NO) in suppressing hepatic inflammation that contributes towards the severity of NAFLD.

\section{Sunlight-Derived Ultraviolet Radiation-A Systemic Modulator of Inflammation}

Ultraviolet radiation (UVR) derived from the sun has both local and systemic effects on health. Skin exposure to UVR induces several immune effector molecules, including vitamin $\mathrm{D}$, NO, heme oxygenase, cis-urocanic acid and serotonin (Figure 1, reviewed in [8]). The UVR spectrum is divided into three distinct biologically active wavelength bands: UVA (315-400 nm), UVB (280-315 nm) and UVC (100-280 nm); and, since the latter does not penetrate the ozone layer of the atmosphere it will not be discussed here. UVB is largely absorbed in the epidermis while around 30\% of UVA reaches the dermis. Here, we discuss the roles of vitamin D, NO and heme oxygenase as immune and inflammatory modulators induced by UVR.

Vitamin $\mathrm{D}_{3}$ is formed when 7-dehydrocholesterol in skin cells, predominantly keratinocytes, absorb UVB photons. Upon binding to vitamin D binding protein, vitamin D circulates to the liver for hydroxylation at the 25-position (to form 25(OH)D) and subsequently to the kidney for hydroxylation to form active, but short-lived, 1,25-dihydroxyvitamin $\mathrm{D}\left(1,25(\mathrm{OH})_{2} \mathrm{D}\right)$ (Figure 1). The half-life of $25(\mathrm{OH}) \mathrm{D}$ is $30-40$ days so this is recognized as the storage circulating form. We have recently reviewed the effects of vitamin D on the immune system [9,10]. Most immune cells (and epithelial cells), express the inducible enzyme, CYP27B1 ( $1 \alpha$-hydroxylase), so they too can make $1,25(\mathrm{OH})_{2} \mathrm{D}$, and to high levels (up to $1 \mathrm{nM}$ ) for autocrine and paracrine effects at the local tissue level [11]. Innate immunity is our first line of defense against microbes, and macrophages and dendritic cells of the innate system can be activated through pathogen-recognition molecules (e.g., Toll-like receptors or NOD receptors) to increase CYP27B1 expression and thus, $1,25(\mathrm{OH})_{2} \mathrm{D}$ production. As all immune cells express the vitamin D receptor (VDR), 1,25(OH) $2 \mathrm{D}$ may have autocrine effects to limit immune cell activation and inflammation. Other studies suggest that expression of the VDR is reduced by macrophage differentiation, providing a limit on the potential for these cells to respond to $1,25(\mathrm{OH})_{2} \mathrm{D}$ (reviewed by [12]). In the liver, VDR expression is mainly detected on non-hepatocytes, including sinusoidal epithelial cells, Kupffer cells, and particularly hepatic stellate cells, suggesting that they (and not 
hepatocytes) harbour the capacity to respond quickly to local synthesis of $1,25(\mathrm{OH})_{2} \mathrm{D}$ [13]. Similarly other components of the vitamin D unit (including enzymes that inactivate 1,25(OH)2D; e.g., CYP24A1) may be regulated in response to immune activation (reviewed in [9]). The adaptive immune system is also modulated by $1,25(\mathrm{OH})_{2} \mathrm{D}$, by inhibiting the activation of dendritic cells, decreasing cytokine production and suppressed $\mathrm{T}$ cell activation, and promoting the development of regulatory $\mathrm{T}$ cells.

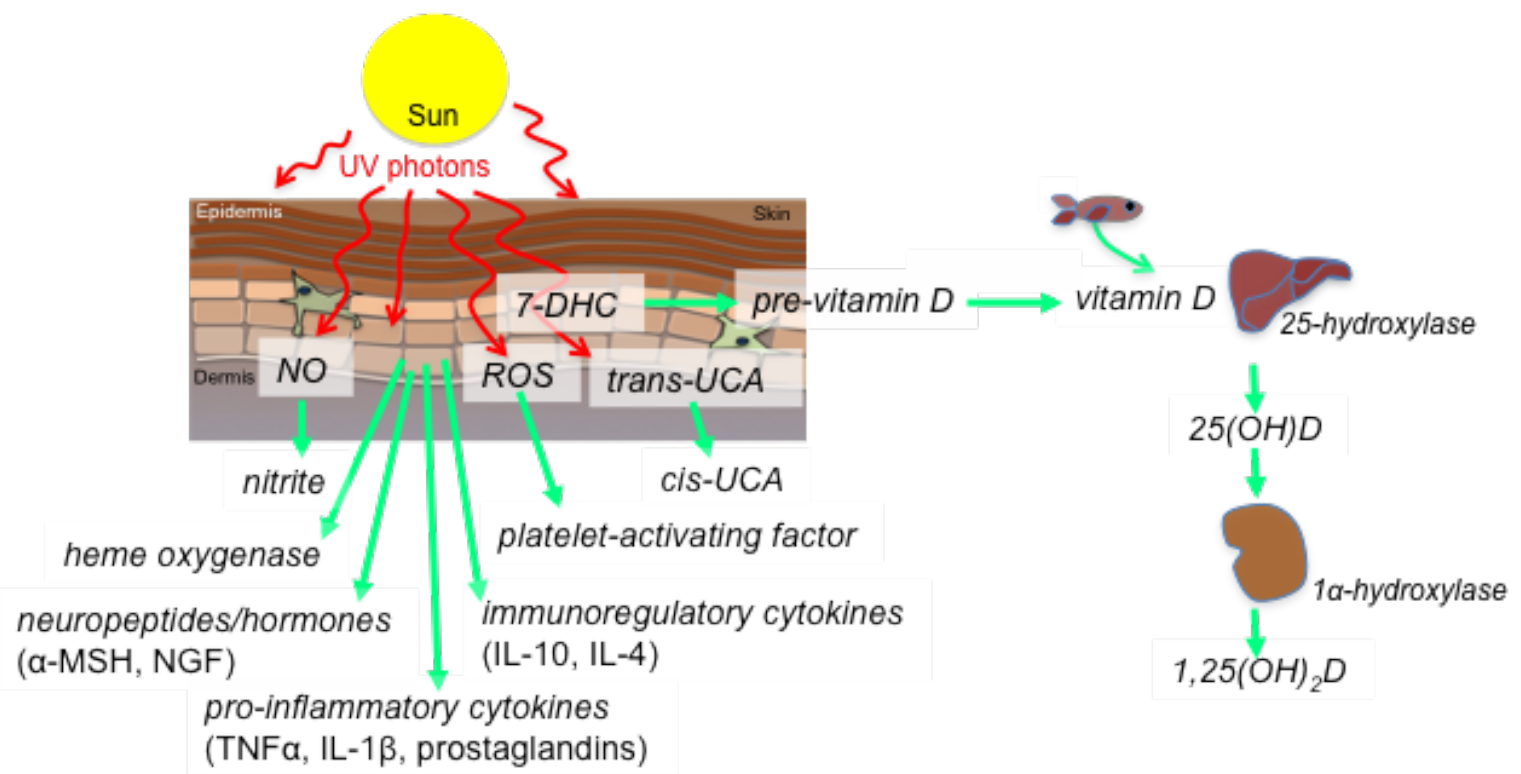

Figure 1. Skin exposure to ultraviolet (UV) photons from sunlight results in the synthesis of effector molecules that modulate immune and metabolic processes. These include: skin release of nitric oxide (NO), increasing serum levels of nitrite; initiation of the conversion of precursor molecules such as reactive oxygen species (ROS), trans-urocanic acid (UCA) and 7-dehydrocholesterol (7-DHC) into platelet-activating factor, cis-UCA and 1,25dihydroxyvitamin $\mathrm{D}\left(1,25(\mathrm{OH})_{2} \mathrm{D}\right.$, calcitriol), respectively; and, the release of heme oxygenase, neuropeptides and neurohormones (e.g., $\alpha$-melanocyte stimulating hormone $(\alpha-\mathrm{MSH})$, nerve growth factor (NGF)), immunoregulatory (interleukin(IL)s-4 and -10) and pro-inflammatory (tumor necrosis factor- $\alpha, \mathrm{IL}-1 \alpha$, prostaglandins) cytokines. Sun exposure of the skin results in systemic production of active vitamin $\mathrm{D}\left(1,25(\mathrm{OH})_{2} \mathrm{D}\right)$ through hydroxylation of vitamin D in the liver and 25-hydroxyvitamin D (25(OH)D) in the kidneys. These events can also occur locally in skin and immune cells that express the hydroxylating enzymes.

NO can be formed by two independent mechanisms: production from L-arginine via the NO synthase (NOS) family of enzymes (neuronal NOS or NOS-I, inducible NOS or NOS-II, and endothelial NOS or NOS-III), and the serial reduction of nitrate $\left(\mathrm{NO}_{3}{ }^{-}\right)$to nitrite $\left(\mathrm{NO}_{2}^{-}\right)$and then to NO. These activities are carried out by a multitude of enzyme systems and are oxygen dependent, although while NOS requires oxygen to form NO, the nitrate reduction pathway is inhibited by its presence. In addition to these enzymatic formation routes NO can also be released from preformed storage forms by light. The mechanisms of release by skin exposure to UVA radiation are discussed below. UVA and UVB radiation induces NOS-II and III expression in murine skin [14,15]. NO constitutively produced from eNOS limits keratinocyte apoptosis in a cGMP-dependent manner, which may thus 'harden' the skin against 
premature apoptosis due to sun exposure. In humans, applying the NOS antagonist N(G)-monomethylL-arginine to the skin prevented UVA-induced immunosuppression to a recall antigen, and depletion of epidermal Langerhans cells, the antigen-presenting cells of the epidermis [15].

Heme oxygenase (HO)-1 is an enzyme that catalyses the degradation of heme, and is typically produced in response to oxidative stress. Heme degradation is associated with the formation of carbon monoxide (CO) and biliverdin; CO can inhibit the production of pro-inflammatory cytokines while biliverdin acts as an antioxidant [16]. HO-1 may play a cytoprotective role in the skin following exposure to sunlight. It is induced in skin by exposure to UVA radiation, where it acts as an antioxidant [17]. UVA-induced HO-1 may reduce the ability of UVB radiation to suppress immune responses through IL-6 and estrogen receptor- $\beta$-dependent mechanisms $[18,19]$.

\section{Hepatic Inflammation Linked with NAFLD}

Chronic and/or excessive liver inflammation exacerbates the severity of NAFLD by killing hepatocytes [20]. Myofibroblasts replace dead hepatocytes, hindering liver function through fibrosis [21]. Hepatocyte death may be caused by profound mitochondrial dysfunction [22], the expression of extracellular signals that promote cell death (e.g., members of the TNF superfamily) and through internal responses that deal with stress, such as the ER stress response, autophagy and production of reactive oxygen or nitrogenous species (reviewed by [20]). Dying hepatocytes perpetuate the pro-inflammatory signal by activating innate immune cells through pattern recognition receptors $[6,20,23]$. Below we discuss briefly the roles of immune cells and central effector molecules that drive inflammation in the liver.

\subsection{What Are the Roles of Resident and Infiltrating Immune Cells in Modulating Liver Inflammation?}

A variety of immune cells contribute to hepatic inflammation, beginning with tissue resident Kupffer (resident macrophages) and natural killer cells, followed rapidly by innate cells (neutrophils, monocytes, inflammatory macrophages), and then finally by infiltrating natural killer T cells, B cells and T cells (reviewed by [6]). Kupffer cells are activated by pathogen- or damage-associated molecular patterns (PAMPs and DAMPs). These molecules are not usually expressed in the liver. During processes of sterile inflammation and tissue injury with progression to NAFLD, DAMPs are expressed/released by hepatocytes to activate receptors on Kupffer and other immune cells [23]. NAFLD is associated with changes to the gut microbiome, which can result in the release of PAMPs and damaging bile acids and toxins that promote inflammation in the gut and liver (reviewed in [3]). This gut-liver axis hypothesis suggests that PAMPs of intestinal origin and DAMPs of liver origin collectively drive hepatic liver inflammation and NAFLD [3,23]. In addition, inflammatory signals may arise from hypertrophic adipocytes and macrophages in adipose tissue [6]. There is overlap in the inflammatory pathways involving PAMPs and DAMPs; those important for the progression of NAFLD include those that involve the toll-like receptors, TLR4 and TLR9 [23]. The collective expression of PAMPs/DAMPs results in proinflammatory cytokine release (e.g., IL-1 $\beta$, IL-6, IL-12, IL-18), the recruitment of immune cells and further hepatocyte apoptosis [6]. 


\subsection{What Are the Central Effector Molecules that Drive Liver Inflammation?}

A shift in the balance of the expression of anti-inflammatory cytokines (e.g., IL-10) towards pro-inflammatory cytokines (e.g., TNF $\alpha$, IL-6) is required for the development of NAFLD [2]. Obesity induces TNF $\alpha$ production by adipocytes, facilitating insulin resistance in these cells and increased lipolysis. This increases the pool of free fatty acids circulating for uptake in the liver and combined with reduced clearance capacity by mitochondria results in the accumulation of triglyerceride droplets in hepatocytes (reviewed by [2]). Pro-inflammatory signals may be derived from liver cells or immune cells migrating into the liver and include cytokines, reactive oxygen and nitrogenous species, chemokines and lipid mediators [6,20]. Many of these mediators are released by keratinocytes or other skin cells following dermal exposure to UVR, including TNF [24], IL-6 [25], prostaglandins [26] and NO [27]. It is therefore counterintuitive that sunlight could prevent liver inflammation and NAFLD. However, there is accumulating evidence that skin exposure to sunlight-derived UVR has potent anti-inflammatory effects in the liver, which we detail below.

\section{Evidence for the Control of Hepatic Inflammation by Ultraviolet Radiation: Vitamin D-Dependent and Independent Pathways}

\subsection{Effects of Phototherapy on Severity of NAFLD}

Phototherapy effectively suppresses the severity of NAFLD in rodent models, through a mechanism that is partially dependent on vitamin D [28,29]. Nakano et al. first demonstrated the efficacy of phototherapy to curtail the severity of NAFLD in male Lewis rats fed a choline-deficient and iron-supplemented L-amino acid (CDAA)-defined diet [28]. The phototherapy was administered for 12 h/day (unknown dose) from an artificial sunlight source (undefined light spectrum) [28]. It reduced hepatocyte apoptosis, inflammation, fibrosis (but not steatosis), insulin/leptin resistance, hepatic and circulating triglyceride levels, and the progression to non-alcoholic steatohepatitis (NASH). In addition, phototherapy suppressed liver levels of TNF $\alpha$ and TGF $\beta$ mRNA and $\alpha$-smooth muscle actin protein [28]. The same phototherapy also reduced liver inflammation and fibrosis in male Zucker fa/fa rats (a leptin-deficient model of obesity) [28]. With skin exposure to UVR, circulating 25(OH)D and $1,25(\mathrm{OH})_{2} \mathrm{D}$ levels increased relative to the control treatment; however, the CDAA diet alone suppressed these levels to $20 \%-30 \%$ of their original concentrations. Supplementation of CDAA-fed rats with $1,25(\mathrm{OH})_{2} \mathrm{D}(0.4 \mu \mathrm{g} / \mathrm{kg}$ orally 3 times/week) reduced the severity of liver hepatitis, in a manner similar to phototherapy, suggesting that some of its effects were dependent on vitamin D [28].

Our studies suggest that UVR has the potential to suppress NAFLD development through vitamin D-dependent and -independent mechanisms. In C57Bl/6 male mice fed a high fat diet for 12 weeks, chronic sub-erythemal UVR (non-burning, low dose, $1 \mathrm{~kJ} / \mathrm{m}^{2}$ UVB twice a week) or erythemal UVR (burning, high dose, $4 \mathrm{~kJ} / \mathrm{m}^{2} \mathrm{UVB}$ once a fortnight) suppressed liver steatosis and lobular ballooning [29]. There was no difference in the liver pathology observed with the different doses of UVR [29]. When male mice were fed a high fat diet (not supplemented with vitamin D), there was no increase in serum 25(OH)D levels with UVR [29], which may have been caused by diminished skin levels of 7-dehydrocholesterol in male mice [30]. Thus, UVR suppressed the severity of NAFLD in a manner that was independent of vitamin D. We compared the effects of UVR to dietary vitamin D, and found that 
while dietary vitamin $\mathrm{D}_{3}$ ( 2000 IU/kg added to diet) did significantly alleviate liver steatosis and ballooning, UVR was more potent. We also observed significant reductions in circulating TNFa levels in mice supplemented with vitamin D [29], but not UVR, suggesting that dietary vitamin D and UVR may suppress NAFLD through differing yet complementary mechanisms.

\subsection{Associations between Vitamin D and NAFLD}

The association between serum 25(OH)D concentrations and the presence and/or severity of NAFLD has been widely investigated in the last two years, building on a small number of studies published prior to 2013 (summarised in Table 1). The majority of these studies were in adults [31-43], with a few addressing associations in childhood and adolescence [44-48]. Most used ultrasound to detect NAFLD [31,32,35-39,41,42,44,47,48], with some relying on serum alanine transaminase (ALT) as a biomarker to detect 'suspected NAFLD' [40,45,46]. A few employed the gold-standard method of liver biopsy to conclusively diagnose NAFLD [33,34,43]. A wide range of ethnicities has been investigated, with studies originating from North America, Europe, Asia and Australia.

Overall, most observational studies support an inverse association between serum 25(OH)D concentrations and NAFLD [31,32,34-44,46-48], independent of potential confounders, such as adiposity and insulin resistance. We recently observed a significant inverse association between serum 25(OH)D concentrations and NAFLD in 17 year-old Western Australian adolescents participating in a population-based cohort $(n=718)$ [44]. A recent meta-analysis of 17 cross-sectional and case-control studies of serum $25(\mathrm{OH}) \mathrm{D}$ concentrations and NAFLD showed that, compared to controls, NAFLD patients were 1.26 times more likely to be vitamin D deficient [49].

The reliability of results from observational studies investigating the association between serum 25(OH)D concentrations and NAFLD may be affected by a number of factors, including the method used to detect NAFLD, the type of assay used to measure serum 25(OH)D concentrations, and the covariates included in the analyses. Although liver ultrasound provides a useful non-invasive estimate of histological hepatic steatosis in large-scale studies [50], it becomes less sensitive when detecting low levels of steatosis. Similarly, ALT concentrations are sometimes used as a biomarker to detect “suspected NAFLD”, but may be relatively insensitive and nonspecific for NAFLD [51,52].

Most observational studies have relied on immunoassay methods, which are highly variable in the measurement of serum 25(OH)D concentrations [53,54], and none have reported using an assay that is certified to the standard reference method developed by the National Institute of Standards and Technology and Ghent University [55]. Not all studies have adequately adjusted for adiposity or season of blood collection, and the sample size of many studies has been small and limited to patients at specific clinical centres. Importantly, evidence to date is limited to cross-sectional analyses, and the possibility of reverse causality cannot be ruled out. Ultimately, although an inverse association between serum 25(OH)D concentrations and NAFLD is widely reported in the current literature, there is no definitive evidence from human studies that supports a causal association between low serum 25(OH)D concentrations and the development or severity of NAFLD. 
Table 1. Associations of circulating 25(OH)D and NAFLD.

\begin{tabular}{|c|c|c|c|c|c|c|c|c|}
\hline Reference & Location & $\begin{array}{c}\text { Sample } \\
\text { Size }\end{array}$ & $\begin{array}{c}\text { Percent } \\
\text { Male }\end{array}$ & Age & NAFLD Detection & Assay Method & $\begin{array}{l}\text { Significant } \\
\text { Association }\end{array}$ & Summary of Findings \\
\hline Barchetta et al., 2011 [31] & Italy & 262 & 53 & Adults & Ultrasound & DiaSorin LIAISON & Inverse & $\begin{array}{c}\text { Low 25(OH)D was associated with NAFLD } \\
\text { independent of metabolic syndrome, } \\
\text { diabetes and insulin-resistance profile }\end{array}$ \\
\hline Bril et al., 2014 [33] & USA & 239 & 85 & 18-70 year & Biopsy & DiaSorin LIAISON & None & $\begin{array}{c}\text { Plasma 25(OH)D was not associated with } \\
\text { insulin resistance, liver fat accumulation or } \\
\text { severity of NASH }\end{array}$ \\
\hline Dasarathy et al., 2014 [34] & USA & 187 & 27 & Adults & Biopsy & $\begin{array}{c}\text { Standard automatic colorimetric } \\
\text { methods }\end{array}$ & Inverse & $\begin{array}{l}\text { Plasma 25(OHD was an independent } \\
\text { predictor of NAFLD activity score }\end{array}$ \\
\hline Hao et al., 2014 [35] & China & 514 & 100 & Adults & Ultrasound & $\begin{array}{l}\text { Electrochemiluminescence } \\
\text { immunoassay (Roche) }\end{array}$ & Inverse & $\begin{array}{c}\text { Serum 25(OH)D was inversely associated } \\
\text { with NAFLD, even in subjects with normal } \\
\text { total body fat }\end{array}$ \\
\hline Jablonski et al., 2013 [36] & USA & 1214 & 26 & $\geq 18$ year & Ultrasound & RIA & Inverse & $\begin{array}{l}\text { Compared with matched controls, NAFLD } \\
\text { patients had significantly lower serum } \\
\text { 25(OH)D }\end{array}$ \\
\hline $\begin{array}{c}\text { Kasapoglu et al., } 2013 \\
\text { [37] } \\
\end{array}$ & Turkey & 613 & 21 & Adults & Ultrasound & Not reported & Inverse & $\begin{array}{c}\text { Low 25(OH)D was associated with NAFLD } \\
\text { among non-obese subjects }\end{array}$ \\
\hline $\begin{array}{c}\text { Kucukazman et al., } 2014 \\
\text { [38] }\end{array}$ & Turkey & 211 & 44 & Adults & Ultrasound & RIA & Inverse & $\begin{array}{l}\text { Serum } 25(\mathrm{OH}) \mathrm{D} \text { was lower in patients with } \\
\text { NAFLD compared to those without NAFLD }\end{array}$ \\
\hline Li et al., 2013 [39] & China & 1248 & 55 & $\geq 20$ year & Ultrasound & DiaSorin RIA & None & $\begin{array}{l}\text { Serum 25(OH)D was not significantly } \\
\text { associated with the presence of NAFLD }\end{array}$ \\
\hline $\begin{array}{l}\text { Liangpunsakul et al., } 2011 \\
\qquad[40]\end{array}$ & USA & 1287 & 50 & $\geq 20$ year & Alanine transaminase & RIA & Inverse & $\begin{array}{c}\text { Significant inverse association between } \\
\text { serum 25(OH)D and unexplained elevation } \\
\text { in alanine aminotransaminase }\end{array}$ \\
\hline Rhee et al., 2013 [41] & Korea & 6567 & 100 & 24-75 year & Ultrasound & $\begin{array}{l}\text { Electrochemiluminescence } \\
\text { immunoassay (Roche) }\end{array}$ & Inverse & $\begin{array}{c}\text { Reduced risk for NAFLD with higher serum } \\
\text { 25(OH)D, independent of obesity and } \\
\text { metabolic syndrome }\end{array}$ \\
\hline
\end{tabular}


Table 1. Cont.

\begin{tabular}{|c|c|c|c|c|c|c|c|c|}
\hline Reference & Location & $\begin{array}{c}\text { Sample } \\
\text { Size }\end{array}$ & $\begin{array}{c}\text { Percent } \\
\text { Male }\end{array}$ & Age & NAFLD Detection & Assay Method & $\begin{array}{l}\text { Significant } \\
\text { Association }\end{array}$ & Summary of Findings \\
\hline Seo et al., 2013 [42] & Korea & 1081 & 32 & 40-69 year & Computed tomography & DiaSorin LIAISON & Inverse & $\begin{array}{c}\text { In subjects with diabetes or insulin } \\
\text { resistance, low vitamin D status was } \\
\text { associated with NAFLD, independent of } \\
\text { visceral obesity }\end{array}$ \\
\hline Targher et al., 2007 [43] & Italy & 120 & 67 & Adults & Biopsy & DiaSorin LIAISON & Inverse & $\begin{array}{c}\text { Compared with matched controls, NAFLD } \\
\text { patients had lower serum 25(OH)D }\end{array}$ \\
\hline Bhatt et al., 2013 [32] & India & 335 & 71 & Adults & Ultrasound & DiaSorin RIA & Inverse & $\begin{array}{c}\text { Low serum 25(OH)D was independently } \\
\text { associated with NAFLD }\end{array}$ \\
\hline Black et al., 2014 [44] & Australia & 994 & 52 & 17 year & Ultrasound & LC-MS/MS & Inverse & $\begin{array}{l}\text { Lower serum 25(OH)D was significantly } \\
\text { associated with NAFLD, independent of } \\
\text { adiposity and insulin resistance } \\
\end{array}$ \\
\hline Katz et al., 2010 [45] & USA & 1630 & 52 & 12-19 year & Alanine transaminase & DiaSorin RIA & None & $\begin{array}{c}\text { No independent association between } \\
\text { vitamin D status and NAFLD after } \\
\text { adjusting for obesity }\end{array}$ \\
\hline Malespin et al., 2014 [46] & $\begin{array}{l}\text { USA (Chinese } \\
\text { American) }\end{array}$ & 407 & 51 & 6-18 year & Alanine transaminase & Immunochemiluminometric assay & Inverse & $\begin{array}{l}\text { Suspected NAFLD was associated with } \\
\text { lower 25(OH)D after adjusting for } \\
\text { BMI, sex, triglycerides, total cholesterol, } \\
\text { LDL, HDL }\end{array}$ \\
\hline Nobili et al., 2014 [47] & Italy & 73 & 64 & 10-15 year & Ultrasound & HPLC & Inverse & $\begin{array}{l}\text { 25(OH)D was inversely associated with } \\
\text { NASH and fibrosis in overweight and obese } \\
\text { children with NAFLD }\end{array}$ \\
\hline Pirgon et al., 2013 [48] & Turkey & 87 & 48 & $11-15$ year & Ultrasound & DiaSorin LIAISON & Inverse & $\begin{array}{l}\text { In obese adolescents, those with NAFLD } \\
\text { had significantly lower 25(OH)D than those } \\
\text { without NAFLD }\end{array}$ \\
\hline
\end{tabular}


An unexplored possibility, which deserves further consideration, is that circulating vitamin D levels may represent a proxy for bodily exposure to sunlight [56], a view consistent with the notion that individuals with lower 25(OH)D concentrations are more susceptible to disease development. Another explanation for the negative associations of vitamin D and NAFLD could relate to an impairment of liver function, where inflammation and the disease process itself might curtail the activity of 25-hydroxylases expressed by hepatocytes, preventing conversion of vitamin D into 25(OH)D. In a rodent model of liver inflammation, ligation of bile ducts induced cholestasis, inflammation and fibrosis in the liver, and inhibited the activity of vitamin D 25-hydroxlase [57]. Furthermore, expression of the 25-hydroxylase, CYP2R1 was inversely related to lobular inflammation in patients with NASH [58]. These studies suggest that hepatic inflammatory processes may hinder circulating 25(OH)D by affecting the hydroxylation of vitamin $\mathrm{D}$ in the liver.

The influence of vitamin D on the development and progression of NAFLD may vary depending on the presence of certain genetic polymorphisms. Indeed, genetic variations in vitamin D metabolism have been identified and may be associated with liver fibrosis and stiffness [59]. VDR expression in the liver and inflammatory cells of chronic liver disease patients is negatively associated with the severity of liver histology in both NASH and hepatitis C patients [58]. VDR expression on cholangiocytes was inversely correlated with steatosis severity, lobular inflammation and NAFLD score, and expression of CYP2R1 in hepatocytes of NASH patients correlated strongly with VDR positivity on liver inflammatory cells. Adams and colleagues previously observed that a common single nucleotide polymorphism (rs222054) in the group specific component gene, which encodes vitamin D binding protein, was associated with NAFLD [60]. Based on these current findings, the genetic variation in vitamin D metabolism deserves further research with respect to NAFLD.

\subsection{Vitamin D Supplementation and NAFLD}

A number of open clinical trials investigating the effects of vitamin D supplementation on NAFLD are currently underway, including three listed at www.clinicaltrials.gov [61] (using vitamin D and non-alcoholic fatty liver disease as keywords). One trial will examine the effects of vitamin $\mathrm{D}_{3}$ (2100 IU/day orally) compared to placebo on serum ALT in patients with NASH over 48 weeks (NCT01571063). In another, the capacity of vitamin $\mathrm{D}_{3}$ (800 IU/day orally) combined with Docosahexaenoic Acid (500 $\mathrm{mg}$ /day orally) to affect NAFLD activity is to be compared with placebo in a pediatric population for 12 months (NCT02098317). A final trial is determining the efficacy of vitamin $\mathrm{D}_{2}$ (50,000 IU/week for 6 weeks, and then bi-weekly for 6 months orally) compared to placebo to affect hepatic triglyceride content in children and adult patients with type-2 diabetes (NCT02132442). All three have estimated enrolments of $<70$.

To our knowledge, there is only one published study investigating the effect of vitamin D supplementation in patients with NAFLD. Sharifi and colleagues [62] investigated the effect of vitamin D supplementation on serum aminotransferases, insulin resistance, oxidative stress and inflammatory biomarkers in adult patients with NAFLD in a parallel, double-blind, placebo-controlled study based in Iran. Patients were supplemented with 50,000 IU $(1250 \mu \mathrm{g})$ of vitamin $\mathrm{D}_{3}(n=27)$ or a placebo $(n=26)$ every 14 days for four months. After adjusting for baseline covariates, including season and body fat percentage, vitamin D supplementation improved serum high-sensitive C-reactive protein and serum 
malondialdehyde concentrations. There was no significant difference between groups in changes in serum ALT, aspartate transaminase, alkaline phosphatase and insulin resistance.

Although the results of Sharifi et al. are relatively unsupportive of a benefit of vitamin D supplementation in adults with NAFLD, the study group was small and the intervention limited to four months [62]. All of the above-mentioned ongoing clinical trials are aiming to recruit similar or smaller group sizes but will test the effects of vitamin $\mathrm{D}$ for longer ( $\geq 6$ months). Furthermore, it will be important to compare the clinical effectiveness of vitamin D supplementation with other successful strategies. Indeed there is good quality evidence to support the beneficial effect of lifestyle changes that promote weight loss (including exercise and diet changes) in reducing the risk of NAFLD [63], and weight loss has been shown to improve the histological features of NASH [64]. Interestingly, exercise alone can have positive effects on NAFLD independently of weight loss [65]. As much exercise is performed outdoors, we suggest that some its benefits may be due to increased sun exposure and the potential bioactivity of vitamin D and/or other UV-induced mediators.

\subsection{Mechanisms by Which Vitamin D Could Suppress Liver Pathology}

Vitamin D may prevent liver pathology and the development of NAFLD through the suppression of related and potentially interacting pathways that involve hepatocyte apoptosis, liver inflammation and fibrosis, oxidative stress, the expression of protective adipokines, and changes to the composition of the gut microbiome.

\subsubsection{Vitamin D Inhibits Hepatocyte Apoptosis}

Feeding rats calcitriol $\left(1,25(\mathrm{OH})_{2} \mathrm{D} ; 1 \mu \mathrm{g} / \mathrm{kg} /\right.$ day, intraperitoneal injection) suppressed the acute rejection of liver allografts $[66,67]$. Vitamin D may have contributed towards allograft survival by inhibiting hepatocyte apoptosis, as suggested by its ability to regulate the expression of apoptosis-associated proteins in the liver, increasing anti-apoptotic Bcl-2 and Bcl-xL proteins, and decreasing pro-apoptotic Bax and Caspase-3 proteins [66]. Calcitriol also inhibited expression of FasL [66], a protein important for the ability of cytotoxic $\mathrm{T}$ cells to target foreign cells.

\subsubsection{Vitamin D Reduces Liver Fibrosis}

Hepatic stellate cells secrete extracellular matrix, which serves as a scaffold for cellular reconstitution and the formation of fibrotic tissue. Active $1,25(\mathrm{OH})_{2} \mathrm{D}$ can directly repress the ability of these cells to form type I collagen [68]. When hepatic stellate cells were obtained from morbidly obese patients with biopsy-proven NAFLD, liver fibrosis was associated with increased fragmentation of the VDR protein [69]. In vitro treatment with $1 \mu \mathrm{M}$ vitamin $\mathrm{D}_{2}$ suppressed the pro-fibrogenic activity of TGF $\beta$ from hepatic stellate cells, modifying the expression of the SMAD2 protein [69]. Other studies suggest that vitamin D may slow the proliferation of hepatic stellate cells (reviewed by [70]). Together, these observations indicate that vitamin D may affect liver fibrosis controlled by hepatic stellate cells through multiple mechanisms. 


\subsubsection{Does Vitamin D Modulate Adipokine Expression?}

Adiponectin is an adipokine (secreted from adipose tissue), which regulates glucose and fatty acid oxidation, but may play a protective role in metabolic processes. Adiponectin may suppress liver fibrosis by inhibiting secretion of TNF $\alpha$ by hepatic stellate cells [71]. Some studies suggest a positive relationship between serum levels of adiponectin and 25(OH)D; however, not all support this link (reviewed in [72]). There is also no agreement in results derived from preclinical studies. Phototherapy increased circulating adiponectin and 25(OH)D levels in CDAA-fed Lewis rats [28], but dietary vitamin $\mathrm{D}$ had no effect on adiponectin levels in Sprague-dawley rats fed a 'westernised diet' that was high in fat and fructose [73] or in mice fed a high fat diet [29]. This might suggest a factor other than vitamin D being released by UVR that reduced plasma adipokine levels. Other adipokines, which may contribute towards the progression of NAFLD include resistin and leptin [71]. However, like adiponectin, there is insufficient evidence, from either preclinical [73,74] or human [75-78] studies to conclusively link their expression with the protective effects of vitamin $\mathrm{D}$.

\subsubsection{Vitamin D Alters the Gut Microbiome and Production of Bile Acids}

As highlighted above, PAMPS derived from the gut may contribute towards liver inflammation through the liver-gut axis. Roth et al [73] hypothesised that in the absence of vitamin D the gut microbiome may change, resulting in enhanced endotoxin exposure and TLR activation, with increased expression of TLR-2, -4 and -9 mRNAs observed in the livers of vitamin D-deficient rats fed a westernised diet [73]. As we have recently reviewed, vitamin D may induce antimicrobials and promote immune tolerance to change the gut microbiome [9]. Other important pathways regulated by vitamin D include the metabolism of bile acids by gut microflora and hepatocytes. Bile acids are produced by hepatocytes and stored in the gallbladder before release into the gut for fat digestion [3]. Bile acids share structural similarity with vitamin D and regulate energy metabolism by interacting with bile acid receptors. Loss in the expression of these receptors has been linked with development of NAFLD and liver carcinogenesis (reviewed in [3]). Vitamin D may directly suppress the synthesis of bile acids by hepatocytes (review in [79]). In addition, changes to the gut microbiome driven by vitamin D deficiency may alter the levels or type of bile acids present in the gut. Indeed, the hepatotoxic bile acid, lithochloric acid [3], interacts with the vitamin D receptor (VDR), which acts as bile acid receptor and targets the acid for degradation [80]. Activation of the VDR by other bile acids or active 1,25(OH) $2 \mathrm{D}$ [80] may enable the degradation of toxic bile acids in the gut and protect from subsequent liver inflammation.

\subsubsection{Vitamin D Suppresses Proinflammatory Cytokines and Mediators of Oxidative Stress}

Increased lobular inflammation and expression of mRNAs encoding the proinflammatory cytokines IL-1 $\beta$, IL-4 and IL-6 was detected in the livers of vitamin D-deficient Sprague-Dawley male rats fed a westernised diet [73]. The increased proinflammatory cytokine expression was linked with TLR activation, which as detailed above may have reflected changes in the gut microbiome and the release of PAMPS. Proinflammatory oxidative stress pathways in the liver may also be regulated by vitamin D. Roth et al. observed enhanced expression of heme oxygenase-1 mRNA in the liver of vitamin D-deficient rats fed the westernised diet [73]. Orally administered vitamin $\mathrm{D}_{3}$ (12 $\mu \mathrm{g} / \mathrm{kg}$ body weight for 
2 weeks) increased the gene expression of antioxidant defence molecules such as glutathione peroxidase and superoxide dismutase in the livers of streptozotocin-induced diabetic rats [81]. In the liver, active $1,25(\mathrm{OH})_{2} \mathrm{D}$ may directly suppress the synthesis of proinflammatory cytokines and oxidative stress molecules.

Vitamin D may also regulate inflammation by affecting bile acid transport in the liver. In vitamin D deficient mice, the expression of the ileal apical sodium-dependent bile acid cotransporter was reduced in the livers of mice with more severe hepatic steatosis and inflammation induced by feeding mice a high fat diet [82]. Supplementation of these mice with intramuscular $1,25(\mathrm{OH})_{2} \mathrm{D}(5 \mathrm{ng} / \mathrm{g}$ body weight, twice a week) reversed the effects of vitamin D deficiency on the expression of this bile acid transporter and the extent of liver inflammation. In addition, there are various indirect mechanisms, such as hepatocyte apoptosis and effects on the gut microbiome, whereby vitamin D targets inflammation (see Figure 2).

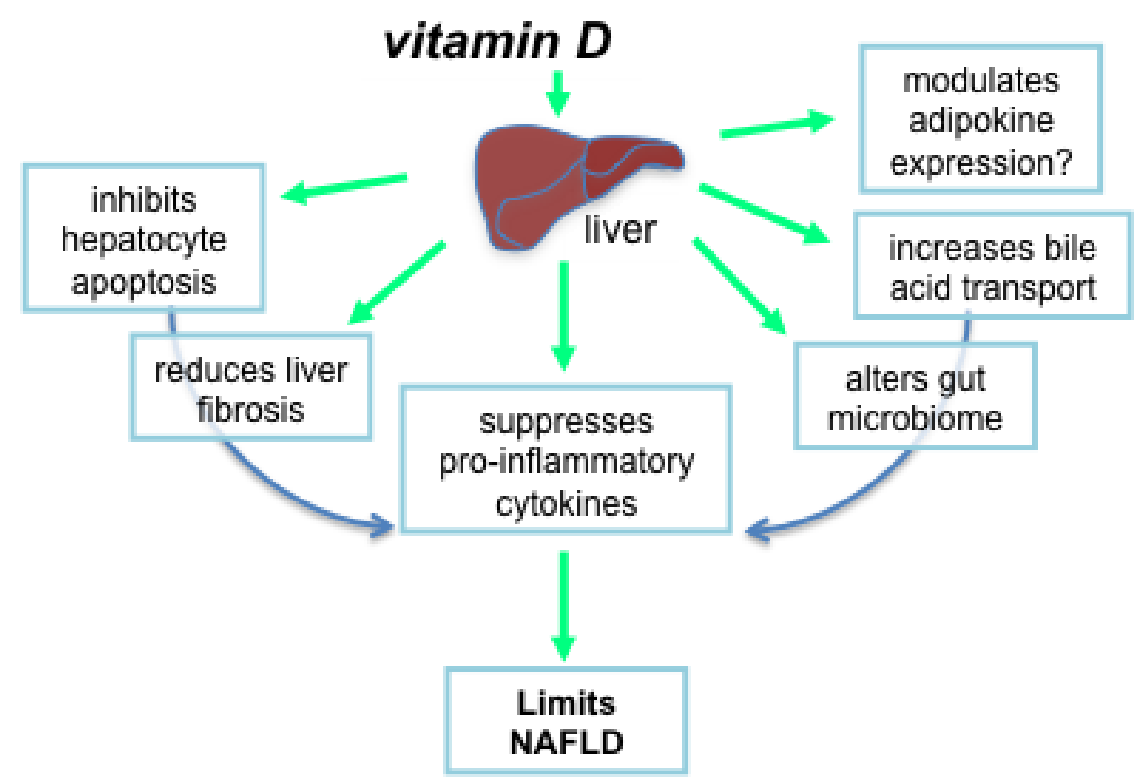

Figure 2. Vitamin D may limit the progression of non-alcoholic fatty liver disease through multiple, potentially interacting mechanisms.

\subsection{Other UVR-Induced Mediators That Could Suppress Liver Inflammation}

Exposure of skin to UVR induces a suite of mediators, many of which could curtail the severity of NAFLD; here, we focus on the potential protective effects of UV-induced NO and heme oxygenase.

\subsubsection{Activation of Dermal Nitric Oxide (NO) by UVR}

NO is an important vasodilator and signaling molecule within the cardiovascular, pulmonary, neuronal and immune systems [83]. However, the role that NO plays in modulating liver inflammation and hepatotoxicity is incompletely understood (reviewed in [84-87]). Factors that may determine whether NO is hepatotoxic or hepatoprotective are how, where and for how long it is produced in the liver. NO synthases convert intracellular L-arginine into citrulline and NO. Expression of endothelial (e)NOS is constitutive and has beneficial effect on the vasculature, while inducible (i)NOS is generated by stress and results in sustained NO production at much higher levels, inducing nitrosative stress 
(reviewed in [20]). Of relevance here is the ability of $1,25(\mathrm{OH})_{2} \mathrm{D}$ to regulate NO synthesis. Treatment of human endothelial cells with $1,25(\mathrm{OH})_{2} \mathrm{D}$ increased the expression of NO through activation of eNOS [88], and VDR mutant mice have a lower bioavailability of NO due to reduced eNOS expression in their vasculature, leading to endothelial dysfunction and increased arterial stiffness [87]. In contrast, $1,25(\mathrm{OH})_{2} \mathrm{D}$ inhibited iNOS expression and reduced NO production by LPS-stimulated macrophages (RAW264.7 cells) at physiologically-relevant doses [89]. Similarly, 1,25(OH) $2 \mathrm{D}$ administration selectively inhibited expression of the inducible cyclooxygenase isoform, COX-2, an enzyme implicated in inflammation, in cultured macrophages [90] and prevented symptoms of allergic asthma by suppressing iNOS in rats [91]. These studies suggest that UV-induced 1,25(OH) $2 \mathrm{D}$ might promote the expression of eNOS by endothelial cells to increase constitutive expression of NO, protecting hepatocytes from nitrative/oxidative injuries caused by a NO burst invoked by iNOS. Further chemical reactions of $\mathrm{NO}$ with superoxide form peroxynitrite $\left(\mathrm{ONOO}^{-}\right)$, and reduce inflammation by downregulating COX-2 expression. In addition, an alternate pathway (known as the nitrate-nitrite-nitric oxide pathway) for NO production exists, where the anions nitrate and nitrite are reduced back to NO [92]. The relative contribution of these pathways to the formation of dermal NO storage forms [27] and hepatic protection is currently unclear.

Skin exposure to UVR mobilizes NO bioactivity from skin, increasing serum nitrite levels within 20 min of skin exposure, with downstream beneficial suppressive effects on blood pressure [93]. These effects were independent of NOS, suggesting an important role for pre-formed cutaneous stores of NO, which were detected in the upper layers of the epidermis [93]. Similarly, we observed increased levels of NO in the dermis of mice exposed to UVR, and the NO donor, SNAP [29]. In mice fed a high fat diet, the extent of liver steatosis and lobular ballooning was significantly reduced by twice-weekly treatment with the NO donor, SNAP, or low-dose irradiation with UVR $\left(1 \mathrm{~kJ} / \mathrm{m}^{2} \mathrm{UVB}\right)$, with the effects of UVR reversed by the NO scavenger CPTIO [29]. The mild blood pressure lowering effects of UVR might be explained by the dilation of small blood vessels in the skin secondary to the release of a mediator such as NO acting in an autocrine fashion. In contrast, hepatic protection by UVR would demand the transduction of bioactivity from the skin to the circulation with subsequent transport to the target organ in a paracrine fashion. The precise mechanism by which UVR-induced mobilization of NO bioactivity reduces the severity of NAFLD is unknown; however, one means could be through regulation of hepatocyte viability. Alternatively, NO may act as an antioxidant [94], leading to the inhibition of reactive oxidant species induced lipid oxidation. NO is also known to modulate mitochondrial function and biogenesis [95], and as already discussed, hepatocyte death may be promoted by mitochondrial dysfunction [22], but further studies are necessary.

\subsubsection{NO-Mediated Upregulation of Heme Oxygenase Expression}

There is uncertainty about the role of HO-1 in the liver and how its expression may affect the severity of NAFLD. Hepatic HO-1 protein levels are increased in the liver in patients with NASH relative to steatosis-positive controls [96], and there are reports of increased HO-1 mRNA, protein and/or activity in the livers of rodents with NAFLD [74,97,98]; yet other preclinical studies do not support these findings [99-101]. Interestingly, exposure of skin to UVA radiation increased activity of HO-1 in both the skin and liver [102], perhaps indicating a hepato-protective effect for UV-induced HO and control 
of NAFLD. Indeed, feeding Zucker-Diabetic-Fatty rats heme (twice weekly, $30 \mathrm{mg} / \mathrm{kg}$ intraperitoneally) upregulated HO-1 activity in the liver, attenuated hepatic inflammatory cytokine expression, hepatocyte ballooning and fibrosis [103]. As detailed above, our studies demonstrate that NO is released from dermal storage forms by UVR [94]. NO may increase HO-1 expression in a variety of tissues ([104]), There may be a role for NO-induced HO-1 in the development of NAFLD, but further mechanistic studies are required.

\section{Conclusions}

Here we review how chronic skin exposure to sunlight-derived UVR may control the development of NAFLD. In addition to vitamin D, UVR induces the production of mediators such as NO and HO-1, which may contribute towards the protective effects of sunlight through a variety of mechanisms that suppress liver inflammation. Chronic skin exposure to UVR may halt the development of NAFLD [28,29], but we do not know whether it is possible to intervene; that is, can UVR or its mediators be used to treat already established NAFLD? Additional studies are required to test whether the observed associations of increased circulating 25(OH)D and positive pre-clinical findings for reduced NAFLD incidence/severity can be translated into recommendations for vitamin D supplementation in the clinic.

\section{Acknowledgments}

We acknowledge funding from the BrightSpark Foundation, the University of Western Australia, the Telethon Kids Institute, the UK Medical Research Council, and the National Health and Medical Research Council (Australia).

\section{Author Contributions}

SG conceived this review and wrote the first draft of the manuscript. PH and LJB contributed towards the design and writing of this review. MF and RW contributed to part of the writing and edited the manuscript.

\section{Conflicts of Interest}

The authors declare no conflict of interest.

\section{References}

1. LaBrecque, D.; Anania, F.; Ferenci, P.; Ghafoor Khan, A.; Goh, K.-L.; Hamid, S.S.; Isakov, V.; Lizarzabal, M.; Mojica Pernaranda, M.; Rivera Ramos, J.F.; et al. Nonalcoholic Fatty Liver Disease and Nonalcholic Steatohepatitis; World Gastroenterology Organisation: Milwaukee, WI, USA, 2012.

2. Berlanga, A.; Guiu-Jurado, E.; Porras, J.A.; Auguet, T. Molecular pathways in non-alcoholic fatty liver disease. Clin. Exp. Gastroent. 2014, 7, 221-239.

3. Lade, A.; Noon, L.A.; Friedman, S.L. Contributions of metabolic dysregulation and inflammation to nonalcoholic steatohepatitis, hepatic fibrosis, and cancer. Curr. Opin. Oncol. 2014, 26, 100-107.

4. Day, C.P.; James, O.F. Steatohepatitis: A tale of two "hits"? Gastroenterology 1998, 114, 842-845. 
5. Feldstein, A.E.; Werneburg, N.W.; Canbay, A.; Guicciardi, M.E.; Bronk, S.F.; Rydzewski, R.; Burgart, L.J.; Gores, G.J. Free fatty acids promote hepatic lipotoxicity by stimulating tnf-alpha expression via a lysosomal pathway. Hepatology 2004, 40, 185-194.

6. Ganz, M.; Szabo, G. Immune and inflammatory pathways in nash. Hepatol. Inter. 2013, 7, 771-781.

7. Tilg, H.; Moschen, A.R. Evolution of inflammation in nonalcoholic fatty liver disease: The multiple parallel hits hypothesis. Hepatology 2010, 52, 1836-1846.

8. Hart, P.H.; Gorman, S.; Finlay-Jones, J.J. Modulation of the immune system by UV radiation: More than just the effects of vitamin D? Nat. Rev. Immunol. 2011, 11, 584-596.

9. Lucas, R.M.; Gorman, S.; Geldenhuys, S.; Hart, P.H. Vitamin D and immunity. F1000prime Reports 2014, 6, 118.

10. Hart, P.H.; Gorman, S. Exposure to UV wavelengths in sunlight suppresses immunity. To what extent is uv-induced vitamin D3 the mediator responsible? Clini. Biochem. 2013, 34, 3-13.

11. Kundu, R.; Chain, B.M.; Coussens, A.K.; Khoo, B.; Noursadeghi, M. Regulation of CYP27B1 and CYP24A1 hydroxylases limits cell-autonomous activation of vitamin D in dendritic cells. Eur. J. Immunol. 2014, 44, 1781-1790.

12. Bouillon, R.; Carmeliet, G.; Verlinden, L.; van Etten, E.; Verstuyf, A.; Luderer, H.F.; Lieben, L.; Mathieu, C.; Demay, M. Vitamin D and human health: Lessons from vitamin d receptor null mice. Endocr. Rev. 2008, 29, 726-776.

13. Gascon-Barre, M.; Demers, C.; Mirshahi, A.; Neron, S.; Zalzal, S.; Nanci, A. The normal liver harbors the vitamin D nuclear receptor in nonparenchymal and biliary epithelial cells. Hepatology 2003, 37, 1034-1042.

14. Weller, R.; Schwentker, A.; Billiar, T.R.; Vodovotz, Y. Autologous nitric oxide protects mouse and human keratinocytes from ultraviolet B radiation-induced apoptosis. Am. J. Physiol. 2003, 284, 1140-1148.

15. Yuen, K.S.; Nearn, M.R.; Halliday, G.M. Nitric oxide-mediated depletion of langerhans cells from the epidermis may be involved in uva radiation-induced immunosuppression. Nitric Oxide 2002, 6, 313-318.

16. Grochot-Przeczek, A.; Dulak, J.; Jozkowicz, A. Haem oxygenase-1: Non-canonical roles in physiology and pathology. Clin. Sci. 2012, 122, 93-103.

17. Tyrrell, R.M.; Reeve, V.E. Potential protection of skin by acute UVA irradiation-From cellular to animal models. Prog. Biophysics Mol. Biol. 2006, 92, 86-91.

18. Reeve, V.E.; Tyrrell, R.M.; Allanson, M.; Domanski, D.; Blyth, L. The role of interleukin-6 in UVA protection against UVB-induced immunosuppression. J. Invest. Dermatol. 2009, 129, 1539-1546.

19. Reeve, V.E.; Allanson, M.; Cho, J.L.; Arun, S.J.; Domanski, D. Interdependence between heme oxygenase-1 induction and estrogen-receptor-beta signaling mediates photoimmune protection by UVA radiation in mice. J. Invest. Dermatol. 2009, 129, 2702-2710.

20. Brenner, C.; Galluzzi, L.; Kepp, O.; Kroemer, G. Decoding cell death signals in liver inflammation. J. Hepatol. 2013, 59, 583-594.

21. Iwaisako, K.; Brenner, D.A.; Kisseleva, T. What's new in liver fibrosis? The origin of myofibroblasts in liver fibrosis. J. Gastroent. Hepatol. 2012, 27, 65-68. 
22. Martel, C.; Allouche, M.; Esposti, D.D.; Fanelli, E.; Boursier, C.; Henry, C.; Chopineau, J.; Calamita, G.; Kroemer, G.; Lemoine, A., et al. Glycogen synthase kinase 3-mediated voltagedependent anion channel phosphorylation controls outer mitochondrial membrane permeability during lipid accumulation. Hepatology 2013, 57, 93-102.

23. Kubes, P.; Mehal, W.Z. Sterile inflammation in the liver. Gastroenterology 2012, 143, 1158-1172.

24. Nishimura, N.; Reeve, V.E.; Nishimura, H.; Satoh, M.; Tohyama, C. Cutaneous metallothionein induction by ultraviolet B irradiation in interleukin-6 null mice. J. Invest. Dermatol. 2000, 114, 343-348.

25. Nishimura, N.; Tohyama, C.; Satoh, M.; Nishimura, H.; Reeve, V.E. Defective immune response and severe skin damage following UVB irradiation in interleukin-6-deficient mice. Immunology 1999, 97, 77-83.

26. Shreedhar, V.; Giese, T.; Sung, V.W.; Ullrich, S.E. A cytokine cascade including prostaglandin e2, il-4, and il-10 is responsible for UV-induced systemic immune suppression. J. Immunol. 1998, 160, 3783-3789.

27. Mowbray, M.; McLintock, S.; Weerakoon, R.; Lomatschinsky, N.; Jones, S.; Rossi, A.G.; Weller, R.B. Enzyme-independent no stores in human skin: Quantification and influence of uv radiation. J. Invest. Dermatol. 2009, 129, 834-842.

28. Nakano, T.; Cheng, Y.F.; Lai, C.Y.; Hsu, L.W.; Chang, Y.C.; Deng, J.Y.; Huang, Y.Z.; Honda, H.; Chen, K.D.; Wang, C.C., et al. Impact of artificial sunlight therapy on the progress of non-alcoholic fatty liver disease in rats. J. Hepatol. 2011, 55, 415-425.

29. Geldenhuys, S.; Hart, P.H.; Endersby, R.; Jacoby, P.; Feelisch, M.; Weller, R.B.; Matthews, V.; Gorman, S. Ultraviolet radiation suppresses obesity and symptoms of metabolic syndrome independently of vitamin D in mice fed a high-fat diet. Diabetes 2014, 63, 3759-3769.

30. Gorman, S.; Scott, N.M.; Tan, D.H.; Weeden, C.E.; Tuckey, R.C.; Bisley, J.L.; Grimbaldeston, M.A.; Hart, P.H. Acute erythemal ultraviolet radiation causes systemic immunosuppression in the absence of increased 25-hydroxyvitamin D3 levels in male mice. PLOS ONE 2012, 7, e46006.

31. Barchetta, I.; Angelico, F.; Del Ben, M.; Baroni, M.G.; Pozzilli, P.; Morini, S.; Cavallo, M.G. Strong association between non alcoholic fatty liver disease (NAFLD) and low 25(OH) vitamin D levels in an adult population with normal serum liver enzymes. BMC Med. 2011, 9, 85.

32. Bhatt, S.P.; Nigam, P.; Misra, A.; Guleria, R.; Qadar Pasha, M.A. Independent associations of low 25 hydroxy vitamin D and high parathyroid hormonal levels with nonalcoholic fatty liver disease in Asian Indians residing in north India. Atherosclerosis 2013, 230, 157-163.

33. Bril, F.; Maximos, M.; Portillo-Sanchez, P.; Biernacki, D.; Lomonaco, R.; Subbarayan, S.; Correa, M.; Lo, M.; Suman, A.; Cusi, K. Relationship of vitamin D with insulin resistance and disease severity in non-alcoholic steatohepatitis. J. Hepatol. 2015, 62, 405-411.

34. Dasarathy, J.; Periyalwar, P.; Allampati, S.; Bhinder, V.; Hawkins, C.; Brandt, P.; Khiyami, A.; McCullough, A.J.; Dasarathy, S. Hypovitaminosis D is associated with increased whole body fat mass and greater severity of non-alcoholic fatty liver disease. Liver Inter. 2014, 34, 118-127.

35. Hao, Y.P.; Ma, X.J.; Luo, Y.Q.; Ni, J.; Dou, J.X.; Hu, Y.Q.; Zhu, J.A.; Bao, Y.Q.; Jia, W.P. Serum vitamin $\mathrm{D}$ is associated with non-alcoholic fatty liver disease in chinese males with normal weight and liver enzymes. Acta Pharmacol. Sinica 2014, 35, 1150-1156. 
36. Jablonski, K.L.; Jovanovich, A.; Holmen, J.; Targher, G.; McFann, K.; Kendrick, J.; Chonchol, M. Low 25-hydroxyvitamin $\mathrm{D}$ level is independently associated with non-alcoholic fatty liver disease. NMCD 2013, 23, 792-798.

37. Kasapoglu, B.; Turkay, C.; Yalcin, K.S.; Carlioglu, A.; Sozen, M.; Koktener, A. Low vitamin D levels are associated with increased risk for fatty liver disease among non-obese adults. Clin. Med. 2013, 13, 576-579.

38. Kucukazman, M.; Ata, N.; Dal, K.; Yeniova, A.O.; Kefeli, A.; Basyigit, S.; Aktas, B.; Akin, K.O.; Agladioglu, K.; Ure, O.S., et al. The association of vitamin D deficiency with non-alcoholic fatty liver disease. Clinics 2014, 69, 542-546.

39. Li, L.; Zhang, L.; Pan, S.; Wu, X.; Yin, X. No significant association between vitamin D and nonalcoholic fatty liver disease in a chinese population. Dig. Dis. Sci. 2013, 58, 2376-2382.

40. Liangpunsakul, S.; Chalasani, N. Serum vitamin D concentrations and unexplained elevation in alt among us adults. Dig. Dis. Sci. 2011, 56, 2124-2129.

41. Rhee, E.J.; Kim, M.K.; Park, S.E.; Park, C.Y.; Baek, K.H.; Lee, W.Y.; Kang, M.I.; Park, S.W.; Kim, S.W.; Oh, K.W. High serum vitamin D levels reduce the risk for nonalcoholic fatty liver disease in healthy men independent of metabolic syndrome. Endocr. J. 2013, 60, 743-752.

42. Seo, J.A.; Eun, C.R.; Cho, H.; Lee, S.K.; Yoo, H.J.; Kim, S.G.; Choi, K.M.; Baik, S.H.; Choi, D.S.; Yim, H.J., et al. Low vitamin D status is associated with nonalcoholic fatty liver disease independent of visceral obesity in korean adults. PLoS ONE 2013, 8, e75197.

43. Targher, G.; Bertolini, L.; Scala, L.; Cigolini, M.; Zenari, L.; Falezza, G.; Arcaro, G. Associations between serum 25-hydroxyvitamin D3 concentrations and liver histology in patients with non-alcoholic fatty liver disease. NMCD 2007, 17, 517-524.

44. Black, L.J.; Jacoby, P.; She Ping-Delfos, W.C.; Mori, T.A.; Beilin, L.J.; Olynyk, J.K.; Ayonrinde, O.T.; Huang, R.C.; Holt, P.G.; Hart, P.H., et al. Low serum 25-hydroxyvitamin D concentrations associate with non-alcoholic fatty liver disease in adolescents independent of adiposity. $J$. Gastroent. Hepatol. 2014, 29, 1215-1222.

45. Katz, K.; Brar, P.C.; Parekh, N.; Liu, Y.H.; Weitzman, M. Suspected nonalcoholic fatty liver disease is not associated with vitamin D status in adolescents after adjustment for obesity. J. Obes. 2010, 2010, 496829.

46. Malespin, M.; Sleesman, B.; Lau, A.; Wong, S.S.; Cotler, S.J. Prevalence and correlates of suspected nonalcoholic fatty liver disease in chinese american children. J. Clin. Gastroent. 2015, 49, 345-349.

47. Nobili, V.; Giorgio, V.; Liccardo, D.; Bedogni, G.; Morino, G.; Alisi, A.; Cianfarani, S. Vitamin D levels and liver histological alterations in children with nonalcoholic fatty liver disease. Eur. $J$. Endocr. 2014, 170, 547-553.

48. Pirgon, O.; Cekmez, F.; Bilgin, H.; Eren, E.; Dundar, B. Low 25-hydroxyvitamin D level is associated with insulin sensitivity in obese adolescents with non-alcoholic fatty liver disease. Obes. Res. Clin. Pract. 2013, 7, e275-e283.

49. Eliades, M.; Spyrou, E.; Agrawal, N.; Lazo, M.; Brancati, F.L.; Potter, J.J.; Koteish, A.A.; Clark, J.M.; Guallar, E.; Hernaez, R. Meta-analysis: Vitamin D and non-alcoholic fatty liver disease. Aliment. Pharmacol. Ther. 2013, 38, 246-254. 
50. Hernaez, R.; Lazo, M.; Bonekamp, S.; Kamel, I.; Brancati, F.L.; Guallar, E.; Clark, J.M. Diagnostic accuracy and reliability of ultrasonography for the detection of fatty liver: A meta-analysis. Hepatology 2011, 54, 1082-1090.

51. Bedogni, G.; Miglioli, L.; Masutti, F.; Tiribelli, C.; Marchesini, G.; Bellentani, S. Prevalence of and risk factors for nonalcoholic fatty liver disease: The dionysos nutrition and liver study. Hepatology 2005, 42, 44-52.

52. Strauss, R.S.; Barlow, S.E.; Dietz, W.H. Prevalence of abnormal serum aminotransferase values in overweight and obese adolescents. J. Pediatr. 2000, 136, 727-733.

53. Carter, G.D. Accuracy of 25-hydroxyvitamin D assays: Confronting the issues. Curr. Drug Targets 2011, 12, 19-28.

54. Lai, J.K.; Lucas, R.M.; Banks, E.; Ponsonby, A.L. Variability in vitamin D assays impairs clinical assessment of vitamin d status. Intern. Med. J. 2011, 42, 43-50.

55. Binkley, N.; Sempos, C.T. Standardizing vitamin D assays: The way forward. J. Bone Miner. Res. 2014, 29, 1709-1714.

56. Feelisch, M.; Gorman, S.; Weller, R.B. Vitamin D status and ill health. Lancet Diab. Endocrin. 2014, 2, e8.

57. Bolt, M.J.; Sitrin, M.D.; Favus, M.J.; Rosenberg, I.H. Hepatic vitamin D 25-hydroxylase: Inhibition by bile duct ligation or bile salts. Hepatology 1981, 1, 436-440.

58. Barchetta, I.; Carotti, S.; Labbadia, G.; Gentilucci, U.V.; Muda, A.O.; Angelico, F.; Silecchia, G.; Leonetti, F.; Fraioli, A.; Picardi, A., et al. Liver vitamin D receptor, CYP2R1, and CYP27A1 expression: Relationship with liver histology and vitamin D3 levels in patients with nonalcoholic steatohepatitis or hepatitis C virus. Hepatology 2012, 56, 2180-2187.

59. Grunhage, F.; Hochrath, K.; Krawczyk, M.; Hoblinger, A.; Obermayer-Pietsch, B.; Geisel, J.; Trauner, M.; Sauerbruch, T.; Lammert, F. Common genetic variation in vitamin D metabolism is associated with liver stiffness. Hepatology 2012, 56, 1883-1891.

60. Adams, L.A.; White, S.W.; Marsh, J.A.; Lye, S.J.; Connor, K.L.; Maganga, R.; Ayonrinde, O.T.; Olynyk, J.K.; Mori, T.A.; Beilin, L.J.; et al. Association between liver-specific gene polymorphisms and their expression levels with nonalcoholic fatty liver disease. Hepatology 2013, 57, 590-600.

61. U.S. National Institutes of Health. Clinicaltrials.Gov. Avaiable online: https://clinicaltrials.gov/ (accessed on 22 April 2015).

62. Sharifi, N.; Amani, R.; Hajiani, E.; Cheraghian, B. Does vitamin D improve liver enzymes, oxidative stress, and inflammatory biomarkers in adults with non-alcoholic fatty liver disease? A randomized clinical trial. Endocrine 2014, 47, 70-80.

63. Loomba, R.; Cortez-Pinto, H. Exercise and improvements of nafld: Practical recommendations. $J$. Hepatol. 2015, doi:10.1016/j.jhep.2015.1003.1009.

64. Vilar-Gomez, E.; Martinez-Perez, Y.; Calzadilla-Bertot, L.; Torres-Gonzalez, A.; Gra-Oramas, B.; Gonzalez-Fabian, L.; Friedman, S.L.; Diago, M.; Romero-Gomez, M. Weight loss via lifestyle modification significantly reduces features of nonalcoholi steatohepatitis. Gastroenterology 2015, doi:10.1053/j.gastro.2015.1004.1005.

65. Keating, S.E.; Hackett, D.A.; George, J.; Johnson, N.A. Exercise and non-alcoholic fatty liver disease: A systematic review and meta-analysis. J. Hepatol. 2012, 57, 157-166. 
66. Zhang, A.; Wang, Y.; Xie, H.; Zheng, S. Calcitriol inhibits hepatocyte apoptosis in rat allograft by regulating apoptosis-associated genes. Int. Immunopharmacol. 2007, 7, 1122-1128.

67. Zhang, A.B.; Zheng, S.S.; Jia, C.K.; Wang, Y. Role of 1,25-dihydroxyvitamin D3 in preventing acute rejection of allograft following rat orthotopic liver transplantation. Chin. Med. J. 2004, 117, 408-412.

68. Potter, J.J.; Liu, X.; Koteish, A.; Mezey, E. 1,25-dihydroxyvitamin D3 and its nuclear receptor repress human alpha1 (i) collagen expression and type i collagen formation. Liver Internat. 2013, 33, 677-686.

69. Beilfuss, A.; Sowa, J.P.; Sydor, S.; Beste, M.; Bechmann, L.P.; Schlattjan, M.; Syn, W.K.; Wedemeyer, I.; Mathe, Z.; Jochum, C., et al. Vitamin D counteracts fibrogenic TGF-beta signalling in human hepatic stellate cells both receptor-dependently and independently. Gut 2015, 64, 791-799.

70. Kwok, R.M.; Torres, D.M.; Harrison, S.A. Vitamin D and nonalcoholic fatty liver disease (nafld): Is it more than just an association? Hepatology 2013, 58, 1166-1174.

71. Giby, V.G.; Ajith, T.A. Role of adipokines and peroxisome proliferator-activated receptors in nonalcoholic fatty liver disease. World J. Hepatol. 2014, 6, 570-579.

72. Husemoen, L.L.; Skaaby, T.; Martinussen, T.; Jorgensen, T.; Thuesen, B.H.; Kistorp, C.; Jeppesen, J.; Thyssen, J.P.; Meldgaard, M.; Szecsi, P.B., et al. Investigating the causal effect of vitamin D on serum adiponectin using a mendelian randomization approach. Eur. J. Clin. Nutr. 2014, 68, 189-195.

73. Roth, C.L.; Elfers, C.T.; Figlewicz, D.P.; Melhorn, S.J.; Morton, G.J.; Hoofnagle, A.; Yeh, M.M.; Nelson, J.E.; Kowdley, K.V. Vitamin D deficiency in obese rats exacerbates nonalcoholic fatty liver disease and increases hepatic resistin and toll-like receptor activation. Hepatology 2012, 55, 1103-1111.

74. Kong, J.; Chen, Y.; Zhu, G.; Zhao, Q.; Li, Y.C. 1,25-dihydroxyvitamin D3 upregulates leptin expression in mouse adipose tissue. J. Endocrinol. 2013, 216, 265-271.

75. Edita, S.; Aleksandar, K.; Dragana, T.N.; Dragana, S.; Branka, K.Z.; Biljana, S.G.; Sanja, S.; Esma, I.R. Vitamin d and dysfunctional adipose tissue in obesity. Angiology 2014, doi:10.1177/ 0003319714543512.

76. Roth, C.L.; Elfers, C.; Kratz, M.; Hoofnagle, A.N. Vitamin d deficiency in obese children and its relationship to insulin resistance and adipokines. J. Obesity 2011, 2011, 495101.

77. Vaidya, A.; Underwood, P.C.; Annes, J.P.; Sun, B.; Williams, G.H.; Forman, J.P.; Williams, J.S. The influence of sodium- and calcium-regulatory hormone interventions on adipocytokines in obesity and diabetes. Metabol. Clin. Exp. 2013, 62, 539-547.

78. Vilarrasa, N.; Vendrell, J.; Maravall, J.; Elio, I.; Solano, E.; San Jose, P.; Garcia, I.; Virgili, N.; Soler, J.; Gomez, J.M. Is plasma 25(OH)D related to adipokines, inflammatory cytokines and insulin resistance in both a healthy and morbidly obese population? Endocrine 2010, 38, 235-242.

79. Han, Y.P.; Kong, M.; Zheng, S.; Ren, Y.; Zhu, L.; Shi, H.; Duan, Z. Vitamin d in liver diseases: From mechanisms to clinical trials. J. Gastroent. Hepatol. 2013, 28, 49-55. 
80. Bouillon, R.; Carmeliet, G.; Lieben, L.; Watanabe, M.; Perino, A.; Auwerx, J.; Schoonjans, K.; Verstuyf, A. Vitamin D and energy homeostasis: Of mice and men. Nature Rev. Endocrinol. 2014, 10, 79-87.

81. George, N.; Kumar, T.P.; Antony, S.; Jayanarayanan, S.; Paulose, C.S. Effect of vitamin D3 in reducing metabolic and oxidative stress in the liver of streptozotocin-induced diabetic rats. $\mathrm{Br}$. $J$. Nutr. 2012, 108, 1410-1418.

82. Kong, M.; Zhu, L.; Bai, L.; Zhang, X.; Chen, Y.; Liu, S.; Zheng, S.; Pandol, S.J.; Han, Y.P.; Duan, Z. Vitamin D deficiency promotes nonalcoholic steatohepatitis through impaired enterohepatic circulation in animal model. Am. J. Physiol. Gastroint. Liver Physiol. 2014, 307, G883-G893.

83. Moncada, S.; Palmer, R.M.; Higgs, E.A. Nitric oxide: Physiology, pathophysiology, and pharmacology. Pharmacol. Rev. 1991, 43, 109-142.

84. Gu, Q.; Cui, Z. Responses to: Nitric oxide as a protector from NAFLD. Hepatology 2015, doi:10.1002/hep.27560.

85. Vinciguerra, M. Nitric oxide as a protector from NAFLD. Hepatology 2014, doi:10.1002/ hep.27562.

86. Kim, P.K.; Zuckerbraun, B.S.; Otterbein, L.E.; Vodovotz, Y.; Billiar, T.R. 'Til cell death do us part: Nitric oxide and mechanisms of hepatotoxicity. Biol. Chem. 2004, 385, 11-15.

87. Suzuki, H.; Menegazzi, M.; Carcereri de Prati, A.; Mariotto, S.; Armato, U. Nitric oxide in the liver: Physiopathological roles. Adv. Nuroimmunol. 1995, 5, 379-410.

88. Molinari, C.; Uberti, F.; Grossini, E.; Vacca, G.; Carda, S.; Invernizzi, M.; Cisari, C. 1alpha,25dihydroxycholecalciferol induces nitric oxide production in cultured endothelial cells. Cell. Physiol. Biochem. 2011, 27, 661-668.

89. Chang, J.M.; Kuo, M.C.; Kuo, H.T.; Hwang, S.J.; Tsai, J.C.; Chen, H.C.; Lai, Y.H. 1-alpha,25dihydroxyvitamin D3 regulates inducible nitric oxide synthase messenger rna expression and nitric oxide release in macrophage-like raw 264.7 cells. J. Lab. Clin. Med. 2004, 143, 14-22.

90. Aparna, R.; Subhashini, J.; Roy, K.R.; Reddy, G.S.; Robinson, M.; Uskokovic, M.R.; Venkateswara Reddy, G.; Reddanna, P. Selective inhibition of cyclooxygenase-2 (COX-2) by 1alpha,25-dihydroxy-16-ene-23-yne-vitamin D3, a less calcemic vitamin d analog. J. Cell. Biol. 2008, 104, 1832-1842.

91. Zhou, Y.; Zhou, X.; Wang, X. 1,25-dihydroxyvitamin D3 prevented allergic asthma in a rat model by suppressing the expression of inducible nitric oxide synthase. Allergy Asthma Proc. 2008, 29, 258-267.

92. Weitzberg, E.; Hezel, M.; Lundberg, J.O. Nitrate-nitrite-nitric oxide pathway: Implications for anesthesiology and intensive care. Anesthesiology 2010, 113, 1460-1475.

93. Liu, D.; Fernandez, B.O.; Hamilton, M.B.; Lang, N.N.; Gallagher, J.M.C.; Newby, D.E.; Feelisch, M.; Weller, R.B. UVA irradiation of human skin vasodilates arterial vasculature and lowers blood pressure independently of nitric oxide synthase. J. Invest. Dermatol. 2014, 134, 1839-1846.

94. Wink, D.A.; Miranda, K.M.; Espey, M.G.; Pluta, R.M.; Hewett, S.J.; Colton, C.; Vitek, M.; Feelisch, M.; Grisham, M.B. Mechanisms of the antioxidant effects of nitric oxide. Antioxid. Redox. Signal. 2001, 3, 203-213.

95. Knott, A.B.; Bossy-Wetzel, E. Impact of nitric oxide on metabolism in health and age-related disease. Diabetes Obes. Metabol. 2010, 12, 126-133. 
96. Malaguarnera, L.; Madeddu, R.; Palio, E.; Arena, N.; Malaguarnera, M. Heme oxygenase-1 levels and oxidative stress-related parameters in non-alcoholic fatty liver disease patients. J. Hepatol. 2005, 42, 585-591.

97. Depner, C.M.; Torres-Gonzalez, M.; Tripathy, S.; Milne, G.; Jump, D.B. Menhaden oil decreases high-fat diet-induced markers of hepatic damage, steatosis, inflammation, and fibrosis in obese LDLR-/- mice. J. Nutr. 2012, 142, 1495-1503.

98. Kathirvel, E.; Chen, P.; Morgan, K.; French, S.W.; Morgan, T.R. Oxidative stress and regulation of anti-oxidant enzymes in cytochrome p4502e1 transgenic mouse model of non-alcoholic fatty liver. J. Gastroent. Hepatol. 2010, 25, 1136-1143.

99. Ahmed, U.; Redgrave, T.G.; Oates, P.S. Effect of dietary fat to produce non-alcoholic fatty liver in the rat. J. Gastroent. Hepatol. 2009, 24, 1463-1471.

100. Jung, T.S.; Kim, S.K.; Shin, H.J.; Jeon, B.T.; Hahm, J.R.; Roh, G.S. Alpha-lipoic acid prevents non-alcoholic fatty liver disease in oletf rats. Liver Internat. 2012, 32, 1565-1573.

101. Panchal, S.K.; Poudyal, H.; Brown, L. Quercetin ameliorates cardiovascular, hepatic, and metabolic changes in diet-induced metabolic syndrome in rats. J. Nutr. 2012, 142, 1026-1032.

102. Widyarini, S.; Domanski, D.; Painter, N.; Reeve, V.E. Photoimmune protective effect of the phytoestrogenic isoflavonoid equol is partially due to its antioxidant activities. Photochem. Photobio. Sci. 2012, 11, 1186-1192.

103. Salley, T.N.; Mishra, M.; Tiwari, S.; Jadhav, A.; Ndisang, J.F. The heme oxygenase system rescues hepatic deterioration in the condition of obesity co-morbid with type-2 diabetes. PLoS ONE 2013, 8, e79270.

104. Motterlini, R.; Green, C.J.; Foresti, R. Regulation of heme oxygenase-1 by redox signals involving nitric oxide. Antioxid. Redox Signal. 2002, 4, 615-624.

(C) 2015 by the authors; licensee MDPI, Basel, Switzerland. This article is an open access article distributed under the terms and conditions of the Creative Commons Attribution license (http://creativecommons.org/licenses/by/4.0/). 